\title{
Are Cushioned Benches Better Option for Classroom Sitting?
}

\author{
Nidhi Vedawala ${ }^{1}$, Sakshi Thakrar ${ }^{2}$ \\ ${ }^{1}$ Tutor, ${ }^{2}$ Assistant Professor, \\ Nootan College of Physiotherapy, Sankalchand Patel University, Visnagar, Gujarat, India-384 315 \\ Corresponding Author: Nidhi Vedawala
}

\begin{abstract}
Background and Purpose: As per our Indian culture "atithi devo bhava" is part of respect and gratitude shown to any guest or visitor by offering to be seated in one of the basic piece of furniture, a chair. Its utilization is in various places like living rooms, offices, dining rooms, in schools and other work places. Chair varies in designs but in some schools comfort zone is not accomplished/fulfilled. Already lifestyle of teenagers have become imperfect due to continuous sitting in wrong postures, this can further lead to various postural changes and health disorders. The purpose of study was to take review about the comfort zone regarding cushioned benches used for classroom sitting in their institutions. So by this survey student's response can be shown and changes can be made by making institutions head aware about basic problem their students and can avoid chronic disorders.

Method: A qualitative method of research was used to conduct online survey of B.CA, polytechnic and physiotherapy college students. Also questions were asked regarding their comfort in classroom sitting along with their suggestions.

Results: After survey $57.83 \%$ agreed that they are facing problem related with class room seating. Also $77.11 \%$ agreed problem emerging after long seating for more than 45 minutes. As per the suggestions from participants in reference of comfortable and sitting for long time period $49.4 \%$ suggested that cushioned benches are extremely helpful for sitting in the classrooms.

Conclusion: After result and outcome of survey it concluded that the cushioned benches can prove better option for seating in classrooms along with comfortable and sitting for long time period.
\end{abstract}

Key Words: Sitting, classroom, cushion, benches.

\section{INTRODUCTION}

Institution being first work place for students it requires special focuses on architectural perfection in terms of student's comfort and ergonomics. According to some studies, it can be said that students are spending approximately 9 hours of sitting per day, also they spend $80 \%$ of their time in chair sitting [1]. For comfortable and continuous sitting, classroom benches must be in accurate dimensions according to ergonomics of student, which can prevent faulty postures and associated disorders like muscle tightness, back pain, compression of diaphragm, poor voice quality etc. ${ }^{[2,3,4]}$
Zacharkow mentioned in 1987 regarding student's lifestyle which have become most sedentary, which results in imperfect postures that children adopts in their childhood followed by permanent postural changes. Milanese's and grimmer 2004 stated in one of article regarding effect of health due to improper dimensions of furniture especially back of thigh, vascular and postural changes etc. ${ }^{[5]}$

In most underdeveloped and developing countries, the anthropometric dimensions of users are not deployed in classroom furniture design. This has severe health as well as learning implications. ${ }^{[6]}$ 
Misalliance of institute's furniture and anthropometric measures of students was found in survey done in West Bengal which in turn need to focus on especially in seating of classroom for student's health and comfort. $^{[7]}$ Murphy also got involved in UNICEF'S humanistic agenda which involved commitment to education of students and furniture used. ${ }^{[8]}$

Classroom seating also affects student's active participation, intelligence and concentration power of students as stated by Sents and Marks in one of their survey. ${ }^{[9,10]}$ Some results in survey showed $90 \%$ of postural malalignment which used Postural Assessment Software (SAPO) and results indicated to improve classroom seating. ${ }^{[11]}$ The current study will prove the utility of cushioned benches which can improve classroom seating.

\section{METHODOLOGY}

Preparation phase: The preparation was conducted prior to data analyses. 1) Key participants- Selection of colleges from where the data will be collected. 2) Preparation of the online questionnaire to record the existing feedback among students.

Implementation phase: 1) Online feedback taken by students. 2) Online Data analysis.

\section{Preparation phase -}

1) Key participants - Selection of colleges from where the data will be collected.

The target population for this research was especially taken from college students belonging to B.CA, Polytechnic and Physiotherapy colleges. The sample from where data was collected comprise of 83 students belonging to first to final years. The inclusion criteria for this data was to logically understand, attempt all questions voluntarily and answer in English language.

2) Preparation of the online questionnaire to record the existing feedback among students: Infrastructure and furniture are important components in the educational systems, also its feedback must be taken by students so as to ensure their fitness.
Online questionnaire was prepared through - www.surveymonkey.com, which include questions regarding comfort zone of students in aspect of benches in their classrooms.

\section{Implementation phase:}

1) Online Data collection: For quick responses participants were collected in classrooms, questionnaire was sent via mail/wats up. And they were asked to give their feedbacks. Data collection was completed from three colleges within four days and was proceeded for data analysis.

2) Data analysis: The data analysis was done with www.surveymonkey.com.The major focus in this study was to identify whether a significant percentage of the student faced discomforts due to classroom seating (Benches) used at their institution and in replacement cushioned benches could be the better option for comfortable seating.

\section{RESULT AND DISCUSSION}

Some studies stated use and benefit of comfortable seating by using Electromyography (EMG) studies and got correlation between functioning of musculoskeletal system with comfortable seating. Also they came to conclusion that above study reduces neck, back stiffness and intervertebral disc pain mostly associated with incorrect sitting for prolong time period. ${ }^{[12-17]}$

B Gligorović stated in his article that correctly designed classroom furniture is one of the most important key factors in regular development of all abilities of school children. Also, he gave importance in raising awareness of the importance of ergonomics for well-being of students. ${ }^{[18]}$ Though there is also a lack of evidence to assess the effect of chairs on children and adolescents in preventing or reducing musculoskeletal symptoms. So here in this article we have done survey on college students for getting their opinion regarding cushioned benches for classroom seating. 


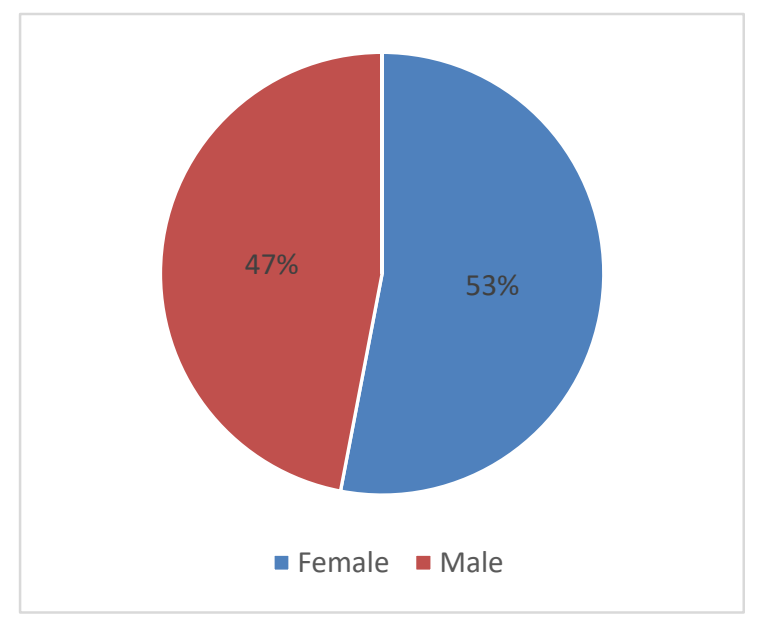

Graph 1: Gender of participants

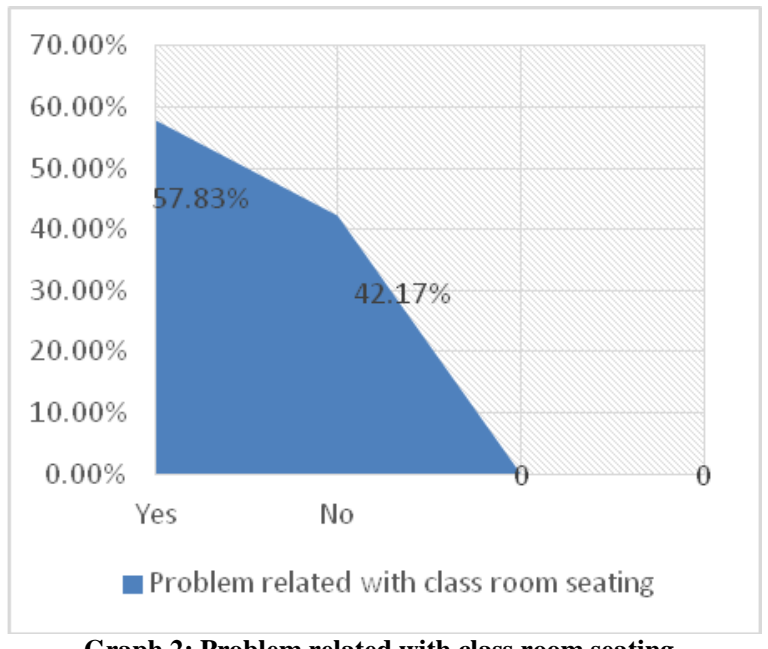

Graph 2: Problem related with class room seating

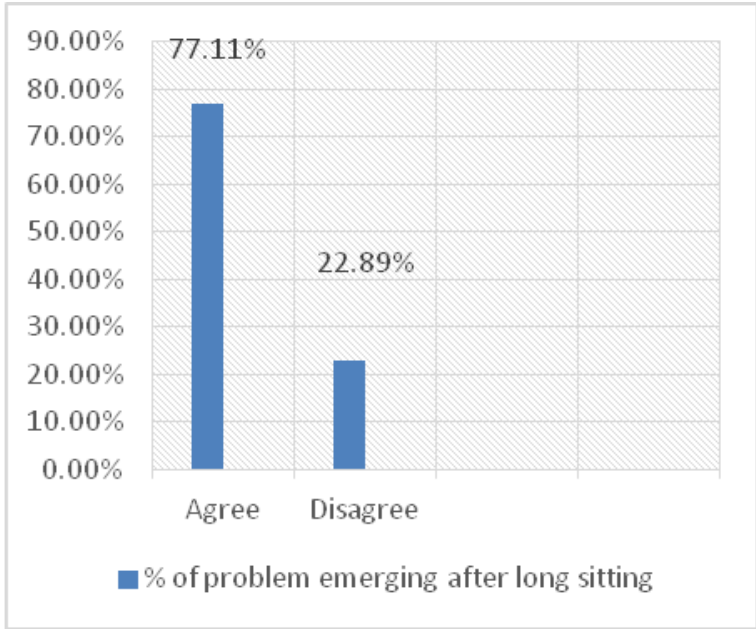

Graph 3: Seating Problem after long seating

After analyzing the data we received 83 feedbacks from College students which included $100 \%$ participation, among them $53 \%$ (44) females, 47\% (39) males participated (Graph 1). As per analysis $57.83 \%$ agreed that they are facing problem related with class room seating (Graph 2), $77.11 \%$ agreed problem emerging after long seating for more than 45 minutes (Graph 3) and $49.4 \%$ suggested that cushioned benches are extremely helpful for sitting in the classrooms along with $18.7 \%$ indicated that cushioned benches are very helpful and $28.92 \%$ marked that it would be somewhat helpful (Graph 4).Overall the cushioned benches can prove better option for seating in classrooms.

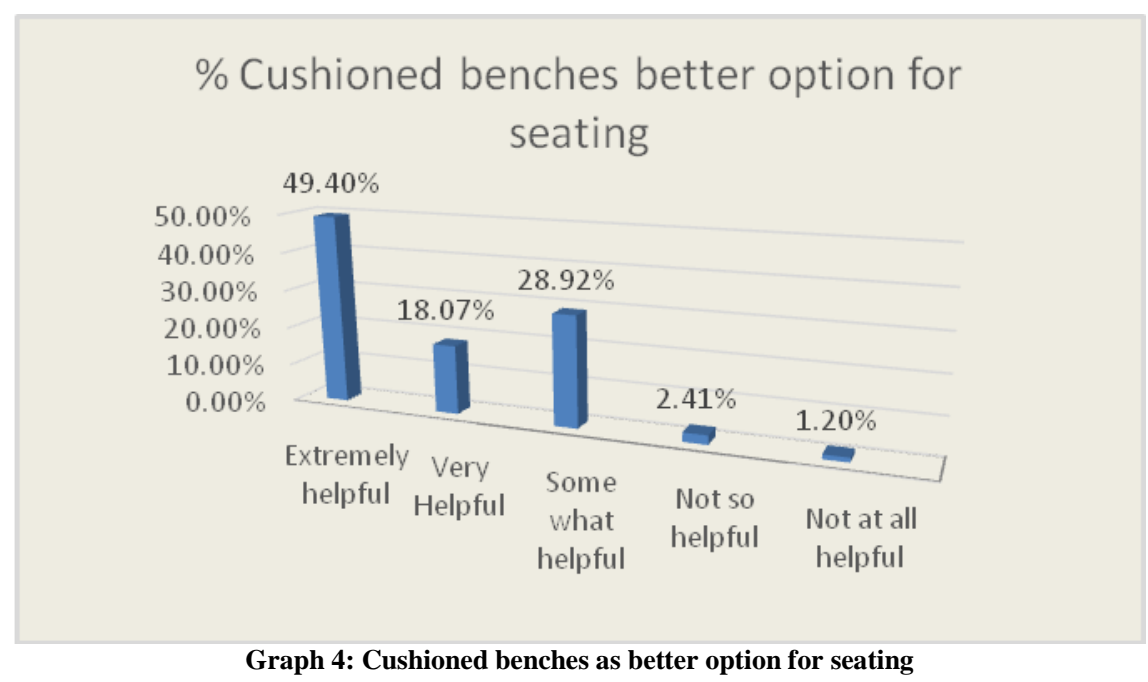

Acknowledgement: None

Conflict of Interest: None
Source of Funding: None

Ethical Approval: Approved 


\section{REFERENCES}

1. Nse A Odunaiya, Dolapo D Owonuwa and Oluwafemi O Oguntibeju. Ergonomic suitability of educational furniture and possible health implications in a university setting. Adv Med Educ Pract. 2014; 5: 1-14. doi: 10.2147/AMEP.S38336

2. ChandaNeloferKhanam, Mahalakshmi V. Reddy \& A.Mrunalini, Designing Student's Seating Furniture for Classroom Environment. Journal of human ecology (Delhi, India) 20(4):241-248. DOI: 10.1080/09709274.2006.11905935

3. H. I. Castellucci, P. M. Arezes, J. F. M. Molenbroek, R. de Bruin \& C. Viviani. The influence of school furniture on students' performance and physical responses: results of a systematic review. Ergonomics. 2017 Jan;60(1):93-110. doi: 10.1080/00140139. 2016.1170889.

4. Michaeleen Doucleff,Can't Get Comfortable In Your Chair? Here's What You Can Do,https://www.npr.org/sections/healthshots/2018/09/24/649169060/cant-getcomfortable-in-your-chair-heres-what-youcan-do[Twitter]

5. Kimberly Gillan, Your chair is the one piece of furniture that's ruining your health.

https://coach.nine.com.au/fitness/sit-

smarter/36be611a-f381-407e-b750cb3ffef8d891

6. B Gligorović, E Desnica and I Palinkaš, The importance of ergonomics in schools secondary technical school students' opinion on the comfort of furniture in the classroom for computer aided design, IOP Conference Series: Materials Science and Engineering, Volume 393, conference 1.

7. Prakash Chandra Dhara, Gurucharan Khaspuri, Soudeep Kumar Sau. Complaints arising from a mismatch between school furniture and anthropometric measurements of rural secondary school children during classwork Article in Environmental Health and Preventive Medicine,January 2009, Volume 14, Issue 1, pp 36-45|[PubMed]

8. Adrian Thompson,Small Furniture, Big Impact,Designing Classroom Furniture that Matters,08/07/2018,30,https://www.interiors andsources.com/article/details/articleid/222 60/title/ classroom-furniture-smallfurniture-big-impact.

9. M S Parvez, F. Parvin, M. M. Shahriar, and G.Kibria; B.E.Sents Design of
Ergonomically fit classroom furniture for primarily school Bangladesh,journal,of Engineering,Volume 2018, Article ID 3543610,9 pages.

10. Jo Earp, Classroom layout - what does the research say?LONG READS,16 March 2017 ,

https://www.teachermagazine.com.au/article s/classroom-layout-what-does-the-researchsay.

11. João Pessoa, Paraíba, Brazil Luiz Bueno da Silvaa, Eliza Juliana da Costa Eulálioa, Antonio SoutoCoutinhoa, Elaine Victor GonçalvesSoaresa and Roberta de Lourdes Silva dos Santosaa, João Pessoa, PB, Analysis on the relationship between the school furniture and the work surface lighting and the body posture of public Middle School students. https://www.ncbi.nlm.nih.gov/pubmed/2231 7608

12. Niemi S, Levoska S, Kemila J, Rekola K, Keinanen-Kiukaanniemi S. Neck and shoulder symptoms and leisure time activities in high school students. J Orthop Sports Phys Ther. 1996;24(1):2529. [PubMed] [Google Scholar]

13. Cho CY, Hwang IS, Chen CC. The association between psychological distress and musculoskeletal symptoms experienced by Chinese high school students. J Orthop Sports Phys Ther. 2003;33(6):344353. [PubMed] [Google Scholar]

14. Smith L, Louw Q, Crous L, GrimmerSomers K. Prevalence of neck pain and headaches: impact of computer use and other associative factors. Cephalalgia. 2009;29(2):250-257. doi: $10.1111 / \mathrm{j} .1468-$

2982.2008.01714.x. [PubMed]

[CrossRef] [Google Scholar]

15. VanDeursen DL, Lengsfeld M, Snijders CJ, Evers JJM, Goossens RHM. Mechanical effects of continuous passive motion on the lumbar spine in seating. J Biomech. 2000;33(6):695-699. doi: 10.1016/S00219290(99)00231-6. [PubMed]

[CrossRef] [Google Scholar]

16. Harrison DD, Harrison SO, Croft AC, Harrison DE, Troyanovich SJ. Sitting biomechanics Part I: review of the Literature? J Manipulative Physiol Ther. 1999;22(9):594-609. doi: 10.1016/S0161-4754(99)70020-

5. [PubMed] [CrossRef] [Google Scholar] 
17. Leivseth G. Spinal shrinkage during work in a sitting posture compared to work in a standing posture. Clin Biomech. 1997;12(78):409-418. [PubMed] [Google Scholar]

18. B Gligorović , E Desnica and I Palinkaš. University of Novi Sad, Technical Faculty "Mihajlo Pupin", ĐureĐakovića bb, 23000 Zrenjanin, Serbia, The importance of ergonomics in schools - secondary technical school students' opinion on the comfort of furniture in the classroom for computer aided design. IOP Publishing IOP Conf. Series: Materials Science and Engineering 393 (2018) 012111 doi:10.1088/1757$899 X / 393 / 1 / 012111$

How to cite this article: Vedawala N, Thakrar S. Are cushioned benches better option for classroom sitting?. Int J Health Sci Res. 2021; 11(9):120-124. DOI: https://doi.org/10.52403 /ijhsr.20210918 